\title{
The green biorefinery concept for the valorisation of pistachio shell by high-pressure $\mathrm{CO}_{2} / \mathrm{H}_{2} \mathrm{O}$ system
}

\author{
Hatice Neval Özbek a, b , Douglas H. Fockink ${ }^{\text {a, c }}$, Derya Koçak Yanık ${ }^{b}$, Fahrettin Göğüş ${ }^{b}$, \\ Rafał M. Łukasik a, * \\ a Unidade de Bioenergia, Laboratório Nacional de Energia e Geologia, I.P., Estrada do Paço do Lumiar 22, 1649-038, Lisbon, Portugal \\ ${ }^{\mathrm{b}}$ Department of Food Engineering, Engineering Faculty, University of Gaziantep, 27310, Gaziantep, Turkey \\ ${ }^{\mathrm{C}}$ Research Center in Applied Chemistry (CEPESQ), Department of Chemistry, Federal University of Paraná - UFPR, P. O. Box 1908, Curitiba, PR, 81531-980, \\ Brazil
}

\section{A R T I C L E I N F O}

\section{Article history:}

Received 18 January 2018

Received in revised form

9 April 2018

Accepted 7 June 2018

Available online 14 June 2018

\section{Keywords:}

Pistachio shell

Carbon dioxide

Biorefinery

Oligosaccharide

Furfural

\begin{abstract}
A B S T R A C T
The use of high-pressure $\mathrm{CO}_{2} / \mathrm{H}_{2} \mathrm{O}$ in valorisation of pistachio shell to produce hemicellulose-derived, oligomeric and monomeric sugars and their further transformation to furfural as well as enzymatic transformation of cellulose-rich solids is presented in this work. Different pre-treatment conditions i.e. temperature ranged from 160 to $200{ }^{\circ} \mathrm{C}$; reaction time varied between 0 and $30 \mathrm{~min}$ and liquid to solid mass ratio between 4 and 8 with constant initial pressure of $\mathrm{CO}_{2}$ of 50 bars were examined. At the optimal pre-treatment conditions, the concentrations of xylose and xylo-oligosaccharide were of 1.7 and $35.5 \mathrm{~g} / \mathrm{L}$. Furthermore, this work demonstrates the high-pressure $\mathrm{CO}_{2}$ catalysed production of furfural in an aqueous/tetrahydrofuran system. For model solution containing a mixture of xylose and acetic acid, the optimised furfural yield was as high as $53.3 \mathrm{~mol} \%$, while for real sample of hemicellulose hydrolysate, the furfural yield of $39.6 \mathrm{~mol} \%$ and the selectivity of $40.0 \mathrm{~mol} \%$ were obtained. Additionally, quantitative glucan to glucose conversion by enzymatic hydrolysis of pre-treated cellulose-rich biomasses was achieved.

The promising results achieved confirm that the valorisation of food residues such as pistachio shell using greener alternative methods involving high-pressure $\mathrm{CO}_{2}$ is an efficient technology, which can be integrated into the biorefinery concept.
\end{abstract}

() 2018 Elsevier Ltd. All rights reserved.

\section{Introduction}

Social, economic and environmental concerns regarding the global energy supplies have been driving to seek for alternative feedstocks and for novel and more sustainable technologies for the production of fuels and chemicals. In this context, the use of a sustainable supply chain of renewable lignocellulosic food industry residues is a potential alternative (Arshadi et al., 2016). Pistachio shell (PS) is one of such examples and is generated in considerable amounts, as the annual world production of pistachios in the last 10 years oscillates between 800 and 900 ktonnes (FAO, 2018). Thus, the valorisation of PS is crucial on the way to achieve sustainable processing of such considerable scale residue. Pre-treatment step is one of the most important and critical stages for the deconstruction

\footnotetext{
* Corresponding author.

E-mail address: rafal.lukasik@lneg.pt (R.M. Łukasik).
}

of PS in order to make biomass available for further conversion to fermentable sugars and other value-added products (Zhao et al., 2017). Several chemical, physical and biological methods of biomass pre-treatment have been developed in last years (Silveira et al., 2015). Among them, the special attention has been focused on the development of more sustainable and greener technologies of biomass pre-treatment (Brandt et al., 2017; Silveira et al., 2015). High-pressure $\mathrm{CO}_{2} / \mathrm{H}_{2} \mathrm{O}$ pre-treatment is advanced in comparison to hydrothermal processes because, the presence of pressurised liquid $\mathrm{CO}_{2}$ favours a series of reactions including carbonic acid formation, which supports the hydrolysis of the biomass hemicellulose fraction into corresponding sugars and simultaneously increases the enzymatic cellulose digestibility (Morais et al., 2014). Furthermore, the use of $\mathrm{CO}_{2}$, contrary to pre-treatments with e.g. mineral acids, does not cause the environmental problem because during the depressurisation, the effect of acidic character of $\mathrm{CO}_{2}$ formed in-situ disappear rising the $\mathrm{pH}$ of the reaction mixture (Morais et al., 2015). Besides the chemical character, a physical 